\title{
Author's toolkit of the state regulation of the development of leasing
}

\author{
Andrei Nechaev $^{1, *}$, Tatiana Romanova ${ }^{2}$, and Maria Tyapkina ${ }^{2}$ \\ ${ }^{1}$ Irkutsk National Research Technical University, 664074, Lermontova str., 83, Irkutsk, Russia \\ ${ }^{2}$ Irkutsk State Agrarian University named after A. A. Ezhevsky, 664038, Molodezhnyi alley, 1/1, \\ Irkutsk, Russia
}

\begin{abstract}
The lack of own funds of enterprises is one of the main problems in resolving issues related to the expansion, the acquisition of new equipment or the replacement of the old one. In contemporary economic conditions, it is leasing that is considered one of the most progressive ways of financing business activity. This financial toolkit is able to provide enterprises with access to the most advanced production technologies and equipment. At the same time, this mechanism is paid insufficient attention in our country. To solve these problems, the authors propose, firstly, the implementation of the algorithm for the development of the reproduction of the material and technical base of organizations based on the use of financial leasing. Secondly, a technique for calculating leasing payments based on a parametric model is suggested, taking into account the application of lowering coefficients. The implementation of the proposed toolkit is aimed at improving leasing relations as one of the most important factors of the development of the material and technical base, and funding for reproduction processes.
\end{abstract}

\section{Introduction}

Leasing as a specific form of funding for reproduction process is an effective tool for solving the issue of dynamic updating of the material and technical base. Unfortunately, this method of update of the material and technical base has not been properly developed in the current economic situation in Russia. At the same time, the efficient operation of production is impossible without a sufficiently high level of mechanization of production processes and without the presence of adequate technical base of organizations.

In many economically developed countries, leasing is considered to be the main tool for financing investments and promoting industrial and technical goods to the consumer. About $15 \%$ of investments in Europe, $30 \%$ in the UK, and 35\% in the USA are financed through leasing.

To solve these problems in our country, first of all, it is necessary to implement a comprehensive algorithm for the development of reproduction of the material and technical base of organizations based of financial leasing.

\footnotetext{
*Corresponding author: n-a-s@ mail.ru
} 


\section{The algorithm for the development of reproduction of the material and technical base of organizations based on financial leasing}

The success of leasing will allow involving additional investments into economy, and ensuring high technical and economic parameters of new technology and compliance with the equal distribution of economic effect from the use of the latest means of production between their producers, companies-lessors and organizations-consumers. However, the exiting mechanism of the state leasing requires a revision and considerable improvement.

In this connection, an algorithm for the development of reproduction of the material and technical base of organizations on the basis of financial leasing is proposed on the Figure 1.

This algorithm consists of three stages and is aimed at the developing mechanism of the state regulation of the activities of organizations, in particular, the state financial leasing of material resources.

At the first stage, it is necessary to choose one of the types of leasing in terms of the payback period of the acquired property:

- $\quad$ - with full payback - when, during the term of the leasing agreement, there is total or close to total depreciation of the property and, accordingly, payment to the lessor of the value of the property;

- $\quad$ - with incomplete payback, in which during the term of one leasing contract, partial depreciation of property occurs and only a part of it is payed off.

At the second stage, it is necessary to analyze how the renewal of the fixed assets in the organization based on the coefficient of renovation of the fixed assets takes place, where the cost of the fixed assets, newly admitted by the organization during a certain period is divided by the cost of the fixed assets available at the end of the reporting period. This ratio represents the relationship of the costs introduced over the past year, to the total value of the fixed assets at the end of the year.

Comparing the values the renewal ratio for the analyzed period with the previous year, one can identify increases or decreases in the coefficient.

With a reduction in the renewal ratio, the lessee is provided with services to reduce the load on leasing payments at the expense of the proposed reduction factors for certain indicators used in calculating the lease payment. This will allow the lessee reducing the cost of payments and purchase the basic asset needed with less load. The coefficient of the interest rate reduction lowers the rate on leasing lending. Due to the rate of reduction of the VAT rate, under special criteria, it is possible to reduce interest [1].

- If the renewal ratio is increased relative to the past analyzed period, it is necessary to calculate how efficiently funds are used in the enterprise using the capital productivity ratio.

Comparison of the capital productivity ratio values for the analyzed period in relation to the previous year allows considering two options. With an increase in the ratio of the capital productivity, the enterprise acquires a leasing of the asset under the standard conditions in force at the time of the transaction. With a reduction in the coefficient of capital productivity, the lessee acquires the asset on more loyal conditions.

The third stage of the algorithm is a final one. At this stage, the organization chooses, by virtue of its capabilities, either the acquisition of the new equipment, or the restored one. At the same time, the trade with the restored machinery is gaining more and more solid positions on the global market and in some countries such sales amounts to $20 \%$ of the total sales of engineering products. 


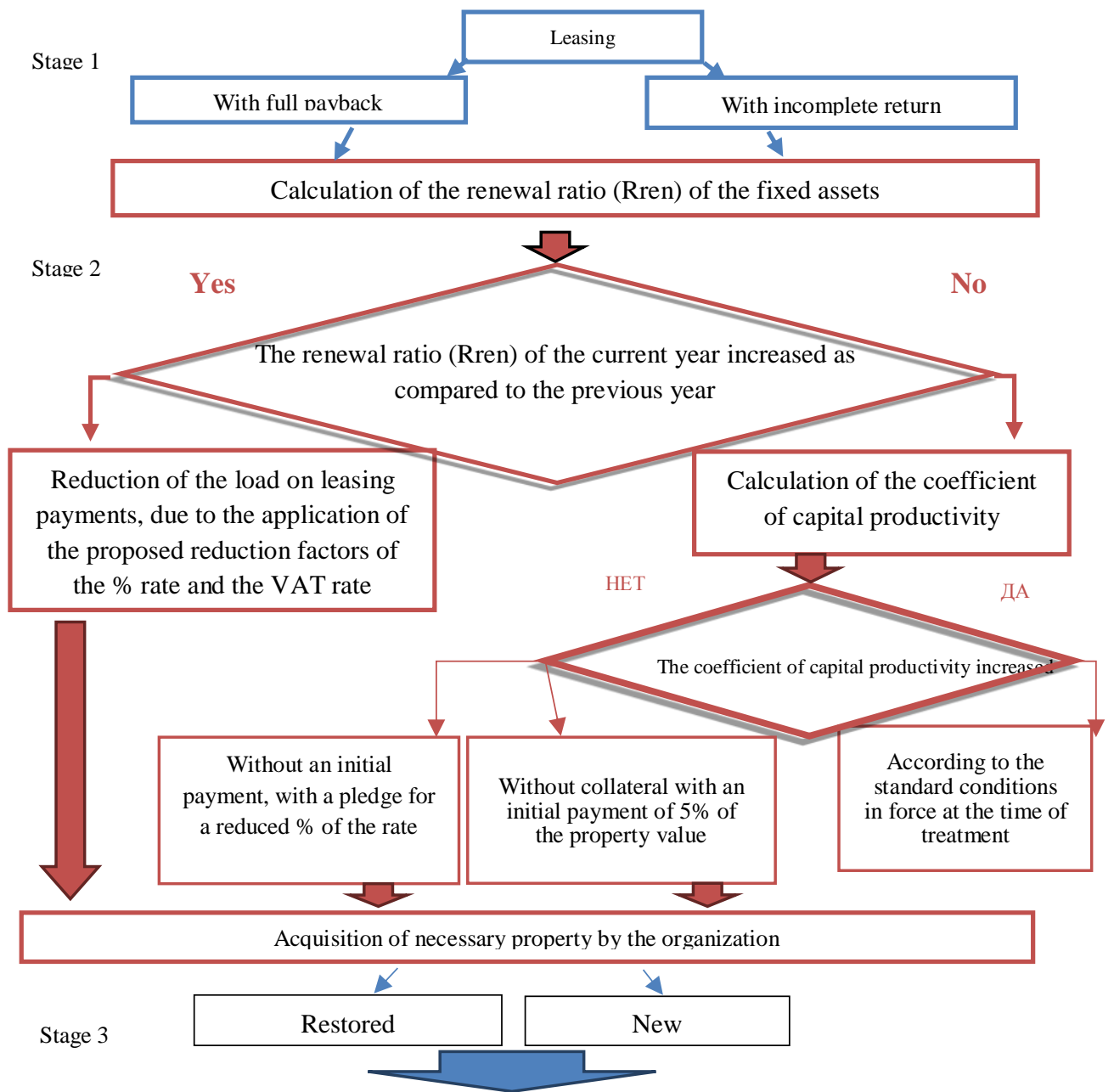

Reproduction of material and technical base of organizations

Fig. 1. Algorithm for the development of reproduction of the material and technical base of organizations on the basis of financial leasing.

\section{Methodology for calculating leasing payments based on a parametric model, taking into account the application of decreasing coefficients}

As a result of the analysis of the problems connected with planning of leasing relations, it is revealed that it is possible to increase their efficiency by application of methods of mathematical modeling for optimization of leasing payments. It should also be noted that in the model of optimizing the structure of monthly leasing payments, it is necessary to take into account the economic interests of both sides of this financial transaction: the lessor and the lessee $[2,3]$. 
In addition, the dynamics of monthly leasing payments, changes in the interest rates on the loan and remuneration to the lessor should be taken into account in the limitations of the model. This issue can be solved using the task of the parametric programming.

When constructing a model, the following conditions must be taken into account:

1. All the required payments of the lessor at each moment $T i(i=1, \ldots, n)$ must be performed by the lessee.

2. A given level $\mathrm{v}$ of the present value $v$ of the lessor's total remuneration shall be provided.

3. The minimum amount of the leased payments should be achieved.

To construct a mathematical model, we introduce the following symbols for the variables. Let $x_{i}$ be the leasing payment in the $i^{\text {th }}$ period (once a month); $a_{i}$ - payment for credit resources used by the lessor to purchase property; $d_{i}$ - depreciation charges accrued by the lessor in the accounting year; $b_{i}$ - amount paid to the lessor for the previous period, including funds previously repaid by the lessee; $p_{i}$ - profit for the $i^{\text {th }}$ period; $y_{i}$-income of the lessor for the $i^{\text {th }}$ period; $B$ - book value of the leased asset; $K_{n}$ - the residual value of the leased asset; $t$ is the VAT rate $(0<t<1)$ for the $i^{t h}$ period, $n$ - the number of $i$-periods equal to 12 months (one calendar year).

In the accepted designations and taking into account the fact that the depreciation rate as a percentage of the initial (replacement) cost of the depreciable property is $2.7 \%$, and the rate for the loan, in percentages per annum, was $20 \%$, we get:

$$
\begin{gathered}
d_{i}=0,027 \cdot B \\
a_{i}=0,2 \cdot\left(\left(B+K_{n}\right) / 2\right)
\end{gathered}
$$

The lessor's remuneration for the provision of property under the leasing agreement, taking into account the commission rate established as a percentage of the average annual residual value of the property - the subject of the contract $-10 \%$ will be written as:

$$
v=0,1 \cdot\left(\left(B+K_{n}\right) / 2\right) \cdot
$$

Calculation of profit for the $i^{\text {th }}$ period is carried out according to the formula:

$$
P_{i}=x_{i}-a_{i}-d_{i}
$$

The income $y_{i}$ of the lessor in the $i^{\text {th }}$ period will be given by the formula:

$$
y_{i}=x_{i}-a_{i}-t \cdot P_{i}
$$

In addition to that, the following conditions must be observed:

- The total income of the lessor for the whole period must be greater than the remuneration paid to him for the provision of property under the leasing agreement:

$$
\sum_{i=1}^{n} y_{i} \geq v
$$

- The lessor's total income is greater than 0: 


$$
\sum_{i=1}^{n} y_{i} \geq 0
$$

In our case, to model leasing payments, we can use the task of the parametric modeling, which is conditioned by the fact that the parameter $b_{i}$ - the amount paid to the lessor for the previous period (including payments previously paid by the lessee) is increased every month by the amount of the monthly payment paid $\left(x_{i}\right)$. In other words

$$
\begin{gathered}
b_{i+1}=b_{i}+b^{\prime}\left(x_{i}\right) \\
0 \leq b_{i} \leq \theta
\end{gathered}
$$

where $\theta$ - the maximum possible amount of payments paid to the lessor, specified in the lease agreement

In this case, the parameter $b_{i}$, is taken into account in the model condition characterizing the residual value of the leased asset $K_{n}$, which is described in the form:

$$
K_{n}=B-\sum_{i=1}^{n} b_{i}+b^{\prime}{ }_{i}\left(x_{i}\right)
$$

Thus, the mathematical model of optimization of monthly leasing payments will have the following form [4].

The criterion of optimality is to minimize the total lease payment.

$$
\sum_{i=1}^{n} c_{i} x_{i} \rightarrow \min
$$

where $c_{i}=e^{-v T i}$ is a coefficient that takes into account the decrease in the amount of the lessor's remuneration at the moment $T_{i}$ considering the residual value of the leased asset.

The conditions of the model, the value of which is described above, will be written in the following form:

$$
\begin{gathered}
P_{i}=x_{i}-a_{i}-d_{i} \\
y_{i}=x_{i}-a_{i}-t \cdot P_{i} \\
K_{n}=B-\sum_{i=1}^{n} b_{i}+b^{\prime}{ }_{i}\left(x_{i}\right) \\
b_{i+1}=b_{i}+b^{\prime}\left(x_{i}\right) \\
d_{i}=0,027 \cdot B \\
a_{i}=0,2 \cdot\left(\left(B+K_{n}\right) / 2\right) \\
v=0,1 \cdot\left(\left(B+K_{n}\right) / 2\right)
\end{gathered}
$$




$$
\begin{array}{r}
\sum_{i=1}^{n} y_{i} \geq v \\
\sum_{i=1}^{n} y_{i} \geq 0 \\
x_{i}, a_{i,} d_{i}, v_{i} \geq 0 \\
0 \leq b_{i} \leq \theta
\end{array}
$$

The solution of the parametric programming problem shows that when the parameter $b_{i}$, characterizing the amount paid to the lessor for the previous period, within the specified limits is changed $b_{i} \in[\mathrm{O} ; \theta]$ monthly lease payment will decrease.

The model (12) - (22) can be modified taking into account the introduction of lowering rates for the loan and VAT. We denote the coefficient of reduction of the loan rate for the variable $\mathrm{k}$, then the parameter of the model (12) - (22) $a_{i}$, taking into account the monthly payment for the loan and the corresponding restriction (16) will be written in the form of:

$$
a_{i}^{\prime}=0,2 k \cdot\left(\left(B+K_{n}\right) / 2\right)
$$

Let $\alpha$ be the refresh rate for the analyzed period, then the parameter $t$ in the model (12) (22) describing the VAT will be equal to:

$$
t^{\prime}=t-0,18 \cdot \alpha
$$

and the restriction (13) takes the form:

$$
y_{i}=x_{i}-a_{i}-t^{\prime} \cdot P_{i}
$$

To optimize leasing payments, two mathematical models are proposed, both of which have a direct effect on the final result.

The first model takes into account the timely repayment of the obligations by the lessee, which will allow obtaining an optimal plan for monthly leasing payments. In the second model, it is proposed to introduce two lowering factors, previously not used in the calculation of leasing, due to which the leasing payment will be substantially reduced [5].

Thus, based on the revealed features, the algorithm for the development of reproduction of the material and technical basis of organizations based on the financial leasing is proposed, consisting of three stages. These stages involve assessing the capabilities of the enterprise under analysis, suggesting options for acquisition under acceptable conditions, based on the level of its equipment, and also provide it an opportunity to choose. The introduction of the proposed author's algorithm and methodology will allow various organizations to update their funds by choosing more suitable conditions, taking into account their financial situation.

\section{References}

1. K. Blackburn, V.T.Y. Hung, Economica, 65, 107-124 (1998)

2. R. Romanov, A. Nechaev, A. Prokopyeva, O. Antipina, Journal of Science and Technology, 9(29), 1544-1553 (2016)

3. A. Nechaev, D. Ognev, O. Antipina, Advances in Economics, Business and Management Research, 38 (2017) 
4. W. H. Janeway, (Cambridge University Press, 2012)

5. A. Nechaev, Y. Barykina, N. Puchkova, Advances in Economics, Business and Management Research, 38 (2017)

6. A. Nechaev, O. Antipina, Modern Applied Science, 2, 88-96 (2015)

7. Ó. Afonso, P.C.Neves, M. Thompson, Metroeconomica, 69 (2018)

8. V. R. Bencivenga, B.D. Smith, Review of Economic Studies, 58 (1991)

9. J. Benson Durham, Emerging Markets Review, 3 (2008)

10. K. Blackburn, V.T. Hung, Economica, 65 (1998)

11. A. Cieślik, Ł.Goczek, World Development, 103 (2018)

12. A.B. Fanta, D. Makina, Evidence from South, 85, (2014)

13. E. M. Grochowski, J. Warschat, R. Conference on Management of Engineering and Technology (2016)

14. J. Haan, R.Pleninger, J, Applied Economics Letters, 25 (2018)

15. T. Koc, E. Bozdag, European Journal of Operational Research, 257 (2017)

16. Q.T.K. Nguyen, P. Almodóvar, International Business Review, 27 (2018)

17. L. Oulasvirta, A.-V. Anttiroiko, Local Government Studies, 43, (2017)

18. J. Schymik, European Economic Review, 102, (2018)

19. B. Stosic, M. Mihic, R. Milutinovic, S. Isljamovic, Technology Analysis and Strategic Management, 29, (2017)

20. N. A. Torugsa, A. Arundel, Research Policy, 46 (2017)

21. P.-C. Wu, C.-C.Lee, Empirica, 45 (2018) 